\title{
Fast Tracks: A Comparison of High Speed Rail in China, Europe and the United States
}

\author{
Junfeng Jiao ${ }^{1}$, Jenna Harbin ${ }^{1}$, Yuan $\mathrm{Li}^{2 *}$ \\ ${ }^{1}$ Department of Urban Planning, Ball State University, Muncie, USA \\ ${ }^{2}$ Department of Urban Planning, Xiamen University, Xiamen, China \\ Email: "liyuan79@xmu.edu.cn
}

Received January 15, 2013; revised February 15, 2013; accepted February 25, 2013

Copyright (C) 2013 Junfeng Jiao et al. This is an open access article distributed under the Creative Commons Attribution License, which permits unrestricted use, distribution, and reproduction in any medium, provided the original work is properly cited.

\begin{abstract}
High speed rail systems have blossomed in technological advances since their debut in the 1960's with the Japanese Shinkansen line. As miles upon miles of tracks increase around the world, bringing added mobility to travelers while decreasing emissions, various technologies are leading the way to a faster tomorrow. This article explores the differences in what countries around the world are using to supply the next generation of travel modes. This paper details the differences in technological implementations from Asia, Europe, and North America. High speed rail systems are far more developed in other countries, especially China, and have required substantial government investment. The United States, with limited HSR development, stands to benefit from the technological advances of others and learn from the economic impacts of HSR in other countries.
\end{abstract}

Keywords: High Speed Rail

\section{Introduction}

High speed rail has the potential to be a great transportation asset to travelers, economies, and the environment. Where implemented, it has typically become the preferred transit mode. It is a technology that has been used throughout various countries, some with more success than others, starting as early as the 1960's [1]. In high density areas, especially those with high volumes of traffic and congestion, a well-developed rail system is a very desirable mode of transportation. In an age of mobility and increased air quality concerns, many are finding high speed rail to be a viable and enjoyable alternative to automobiles and plane travel. Though high speed rail is capable of drastically reducing travel times with maximum speeds well into the $450 \mathrm{~km} / \mathrm{h}$ range or higher, tradeoffs exist in speed versus energy consumption. This still leaves travelers with a transportation option, however, of speeds over $300 \mathrm{~km} / \mathrm{h}$ in many circumstances, drastically reducing the time to a destination. They are investments that take decades to realize a return on investment, but some nations are beginning to see their lines pay off and begin to profit.

Countries with well-developed networks of HSR have seen various types of economic impact. Many have ex-

*Corresponding author. perienced the strengthening of their large, globally active city centers and business hubs as transportation between major cities has become simplified and faster [2]. Many of the dense cities in Europe and Asia were experiencing strong air pollution and traffic congestion issues. High speed rail reduces both of these issues with lower emissions and an attractive and often faster mode of transportation to travelers and workers [2]. Rail networks are not only linking major cities in European countries, but those in other countries as well as the network grows to span across the region. In this article, the various technologies and economic impacts will be reviewed and compared to examine how HSR is changing the global transportation scene.

\section{Asia}

Figure 1 on the next page shows the HSR network in Asia. Japan debuted the first high speed rail system in 1964 with speeds of about $210 \mathrm{~km} / \mathrm{h}$ [1]. Compared to other modern systems, this speed would be considered somewhat modest for current technology, but it held the top spot in the World Speed Survey until 1981 [3]. Also, it sparked an interest for nations around the world in the consideration of long distance travel. The Shinkansen tracks of Japan have grown to stretch fourteen hundred 


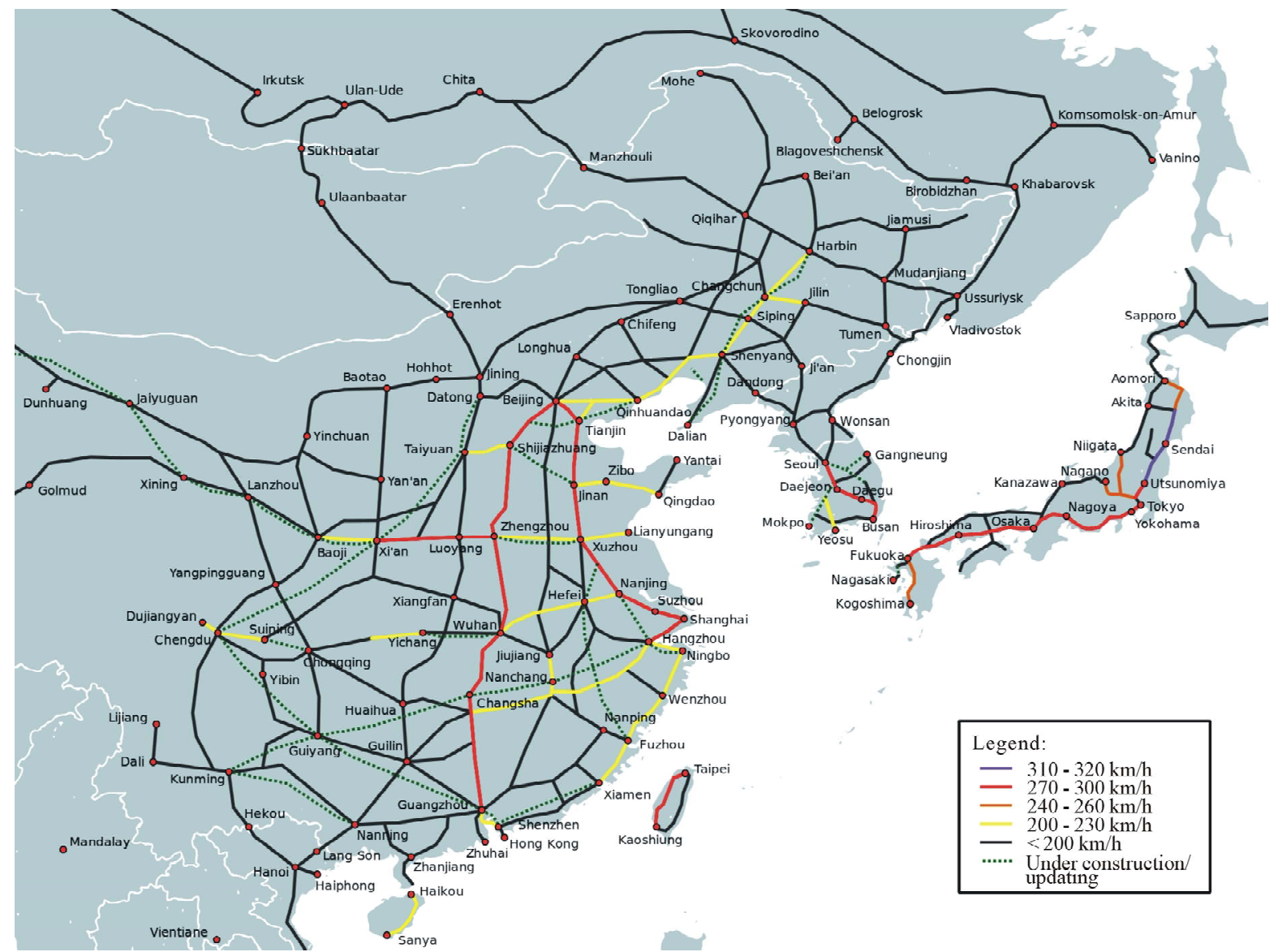

Figure 1. Network of high speed rail systems throughout Asia [16].

miles with speeds slightly under $325 \mathrm{~km} / \mathrm{h}$. The electric trains contain powered axles beneath the train, whereas other countries implemented locomotive-powered, fast trains [1]. Lightweight designs and low maintenance are strong advantages to the Shinkansen technology. Also used in Shinkansen designs is distributed traction, which increases payload space, powers more axels for better adhesion, and regenerative breaking systems that turns slowing down into an energy source [3].

High speed rail (HSR) has become an effective mode of transit in many Asian communities. In Taiwan, HSR has brought many of the major cities and surrounding areas to a travel time of less than one hour, and has connected Kaohsiung and Taipei with a 90-minute trip instead of the previous 4.5-hour railroad trip [4]. Approved in 1995, the HSR in Taiwan was the first major infrastructure project to be undertaken using a Build-OperateTransfer model [5].

The Taiwan High Speed Rail (THSR) is a $345 \mathrm{~km}$ rail corridor designed for maximum speeds of $350 \mathrm{~km} / \mathrm{h}$, with $75 \%$ of the line operating on elevated bridges [5]. The Taiwan HSR system involved an investment of approximately $\$ 16$ billion [6]. The THSR connects areas of manufacturing, business, and administration to bring the export-dependent country within closer operating of its various sectors. Shifts in urban land uses in this region have followed with transportation shifts (e.g. centered on harbors and ports changing to centered on rail stops). The THSR technology is mostly imported and based on the Shinkansen line of Japan, with management systems implemented from European technology [4].

As the rail is located throughout a geologically active area between two subduction zones, it was important to implement designs that could withstand seismic activity. The Tuntzuchiao Fault crosses the HSR line, requiring special engineering for various sections. This prompted special height minimums on earthen embankments and specific bridge supports with some components being somewhat elastic to particular directions of movement so that major loss of life and bridge failures could be avoided.

By far the most extensive high speed rail system is in China. China rail systems are comprised of a variety of different technologies. The Chinese HSR (CHSR) networks synthesize technology from Japan, Germany, and France, while adding in innovations of the country's own [7]. The Shanghai Maglev debuted in 2003 and runs on technology from a German company, reaching top speeds 
of $430 \mathrm{~km} / \mathrm{h}$ [8]. The CHSR line running from Wuhan to Guangzhou is a locally built combination of the Japanese Shinkansen and German ICE trains, with some variations [9].

Obstacles China had to overcome in the quest for leading the world in HSR included topography and geology. The extensive networks race over starkly different geologic bases and large spans of rivers. Three of the HSR bridges in China hold records for span, width, and capacity [7]. Extreme technological precedents were also set in the tunnel construction and speed (up to 350 $\mathrm{km} / \mathrm{h}$ ) through the tunnels of the trains. The CHSR tracks, unlike others using repurposed tracks, was a ground-up design that allows for top speeds over a range of obstacles without having to slow down as repurposed lines require [9]. China uses ballastless tracks that do not use rock material to stabilize them and also has track networks that are seamless, a feat that required heavy research due to varying temperatures across the country [7]. The Chinese rails are nearly all set in concrete slabs of German design, which reduce wear and tear on the wheels and tracks [9]. Chinese-made trains operate worldwide and remain the fastest.

\section{Europe}

Figure 2 shows the network of HSR throughout Europe. In Europe, there are differences in how high speed rail systems are done from details of the larger system down to the way power is supplied. England tends to use a smaller voltage than the norm for the rest of Europe (e.g. $1.5 \mathrm{kV}$ for Europe and $750 \mathrm{~V}$ for England as typical norms). Similarly, HSR in England supplied power via a third rail, whereas other European countries use overhead delivery of power [8]. Some of Europe's old diesel train lines are still in operation, as the fastest diesel trains in operation [1]. In Europe, interconnectivity has grown up alongside high speed rail, with the European Union encouraging the construction of tracks along lines that would be beneficial to national governments. This has given rise to safety and operation standards that are cohesive between countries [1]. European HSR is operated almost entirely on a for-profit basis that does not utilize government subsidy. England's rail system was con-

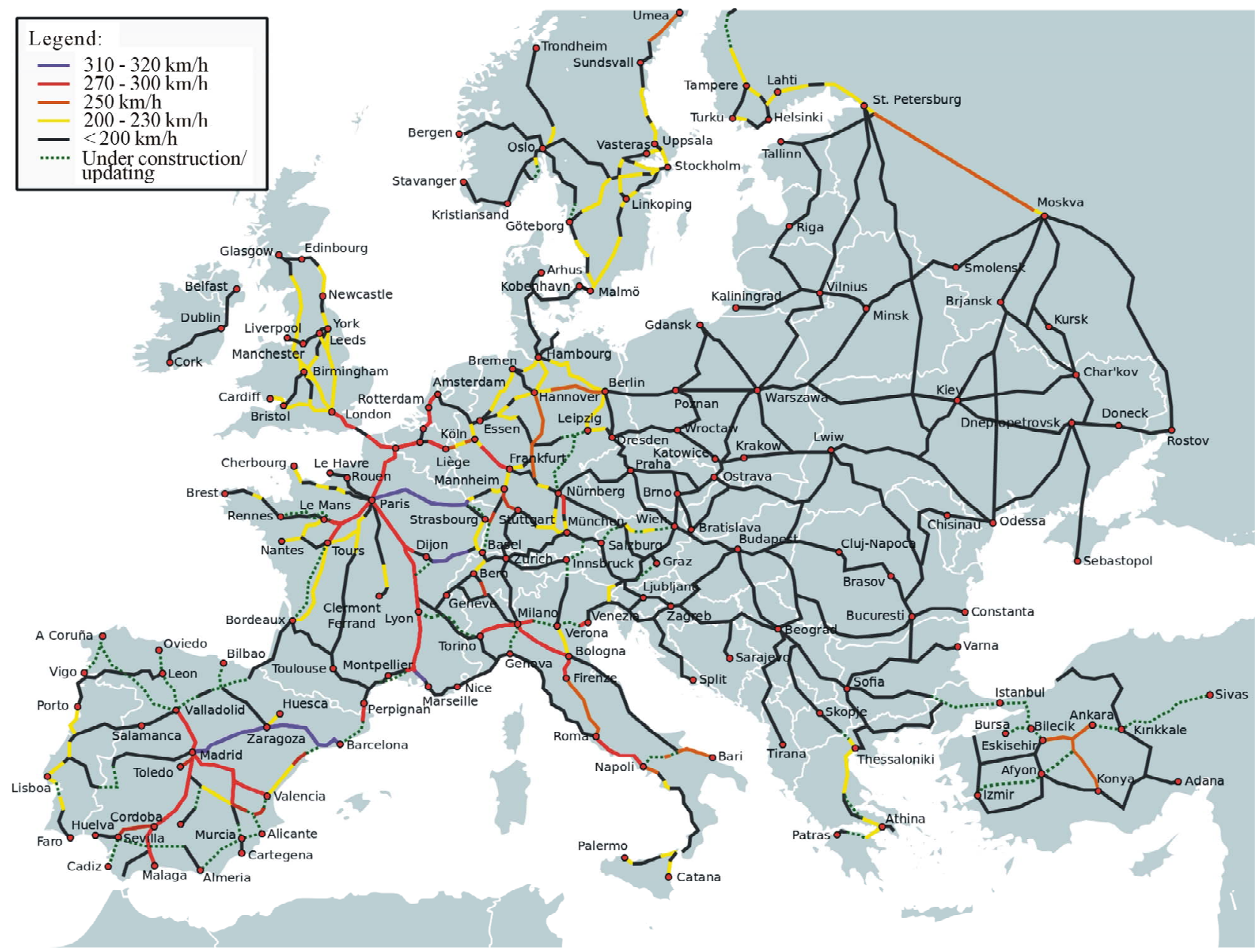

Figure 2. European network of high speed rail systems [17]. 
structed by a government-owned company, but was later leased to private consortium for operations [1].

France started with diesel trains in the 1960's that reached speeds of $125 \mathrm{mph}$. With increasing oil prices in the 1970's, France converted to electric powered trains built by Alstom for a line between Paris and Lyon. The electric trains cut the nearly 270 mile trip to a time of two hours, cementing the usability of the transportation method for riders. In 1981, the TGV debuted as the first HSR that would run not only on its own dedicated lines, but also on regular rail network lines. Trains on the TGV consist of a locomotive on each end with cars in between, with some lines hosting double decker train sets that can hold over 1000 passengers [6]. The HSR network of France today is over 1185 miles and counting, with typical speeds of about $186 \mathrm{mph}$ [1]. French HSR tracks are stabilized using small fragments of crushed stone for a ballasted stabilization system, which is not used in Germany or Japan [7]. Spain and Korea also have high speed lines largely using French TGV technology. Over fifty percent of domestic travel in France is done by TGV [10].

Germany began developing magnetic levitation (maglev) technology for trains while also researching traditional high speed rail. Prohibitive costs stopped maglev from being a viable option for Germany, though it has been used successfully in Shanghai, China, and is planned for Japan. Germany's high speed rail (dubbed ICE trains) system has grown slower but is at nearly 700 miles [1]. The German ICE3 systems implemented the regenerative breaking systems similar to the Shinkansen line [3].

\section{United States}

Figure 3 shows the proposed plans for an HSR system in the United States. The United States has not seen the same boom in HSR construction and usage that other countries have. By underinvesting in high speed rail upgrades and network development, the HSR system in the United States is mostly limited to the line on the east coast. Projects, such as the one in California, have been proposed but have taken over a decade to secure the funding and actually begin the project itself. The California project proposes new HSR tracks that will be capable of speeds of $150 \mathrm{mph}$, which is unique among HSR corridors in the United States [11]. The HSR line in the United States running from Boston to Washington runs on conventional rail systems, and is the only high speed system operating in the United States. Amtrak's Northeast Corridor Mainline (Boston to D.C.) captures 62\% of the travelers going between New York and Washington DC and provides connections to the major airports in the area [11]. The Northeast Corridor (NEC) system is

\section{VISION for HIGH-SPEED RAIL in AMERICA}

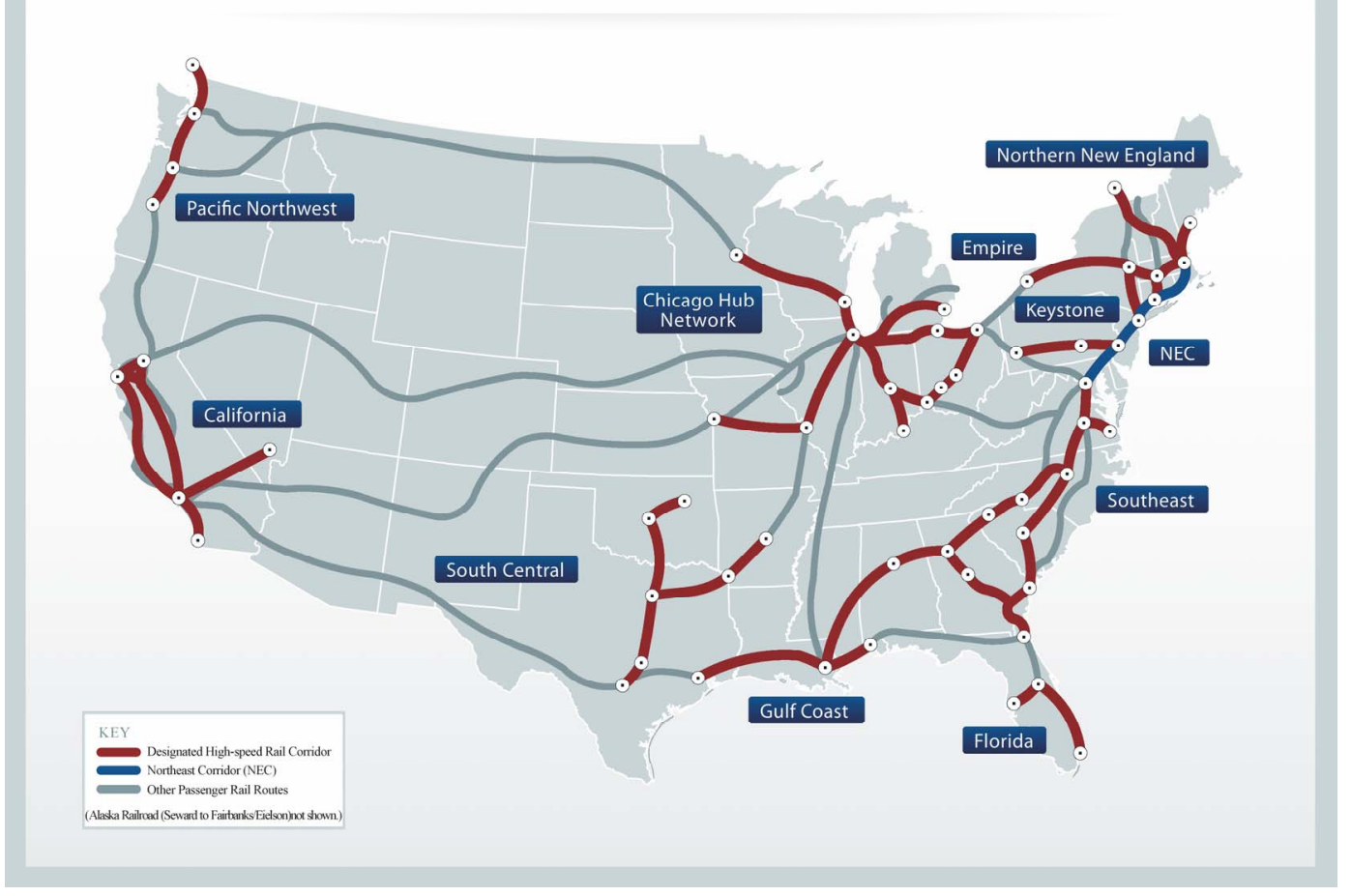

Figure 3. United States high speed rail vision plan [18]. 
Table 1. High speed rail comparison of strengths and weaknesses of various systems around the world.

\begin{tabular}{|c|c|c|c|}
\hline Area & Strengths & Weaknesses & Economic Impacts \\
\hline Asia & $\begin{array}{c}\text { Drastically reduced travel times } \\
\text { between cities [13] Highest speeds } \\
\text { Variety of technologies used and created } \\
\text { for changing terrains and temperatures } \\
\text { Largest network in the world (China) } \\
\text { Longest history of HSR systems }\end{array}$ & $\begin{array}{l}\text { Huge investment from government } \\
\text { Maglev technology cost } \\
\text { substantially more } \\
\text { Stock issues and losses from } \\
\text { global projects [13] }\end{array}$ & $\begin{array}{l}\text { Business can now move inland for } \\
\text { less expensive labor } \\
\text { Construction industries seeing a huge } \\
\text { rise in business as growth occurs [13] }\end{array}$ \\
\hline Europe & $\begin{array}{c}\text { Some lines (French TGV) } \\
\text { have proven profitable [14] } \\
\text { Some lighter weight systems are } \\
\text { less expensive [14] } \\
\text { Maglev research and technology }\end{array}$ & $\begin{array}{c}\text { Not an overall network yet } \\
\text { linking the entire area [14] } \\
\text { Diverts traffic from traditional rail } \\
\text { networks causing them to } \\
\text { run at a deficit [14] }\end{array}$ & $\begin{array}{l}\text { Increased economic concentration } \\
\text { in large cities [14] } \\
\text { Less urban lines have seen } \\
\text { (some limited) development }\end{array}$ \\
\hline $\begin{array}{l}\text { United } \\
\text { States }\end{array}$ & $\begin{array}{l}\text { Future rail projects can benefit from the } \\
\text { technological advances of other countries }\end{array}$ & $\begin{array}{l}\text { Limited Development } \\
\text { Shared tracks reduce } \\
\text { potential speeds }\end{array}$ & $\begin{array}{l}\text { More than } 5 \text { million jobs are within } 5 \mathrm{~km} \text { of } \\
\text { the Northeast Corridor system [15] } \\
\text { California project estimated to produce } 600,000 \\
\text { construction jobs and } 450,000 \text { permanent jobs [15] }\end{array}$ \\
\hline
\end{tabular}

surprisingly still one of the busiest corridors in the world, serving millions of commuters and intercity travelers [12]. However, the underinvestment and high ridership prove difficult for the tracks to handle.

Other Amtrak systems exist in the US, such as the Midwest network and the Pacific Northwest network, but they currently do not reach speeds over $100 \mathrm{mph}$ [9]. United States trains tend to be heavier than their lightweight counterparts across the world, mostly due to a concern over survivability in a crash. However, various lightweight, high speed systems in the world have experienced few to no fatalities in crashes, alluding to the overall safety that can be achieved with good signaling and safety technology in place in HSR systems [11].

The main obstacle to the development of HSR in the United States is funding. It takes substantial financial resources to develop a network that is high speed, efficient, and attractive to travelers [11]. If a train system is not cutting travel times between cities sufficiently, it will not be able to attract the ridership it needs. Other issues include the balance of increasing speed with the variety of track uses. Many of the United States tracks are also used by freight systems, which has successfully worked in other countries but does impose some restrictions on speed and safety if proper technology is not used, which can also be financially encumbering. A strong HSR network in the United States will require the construction of more infrastructures to fit the needs of the technology.

\section{Comparisons}

While other countries have invested hundred s of billions of dollars to develop strong high speed networks, the United States has pour comparatively little into their networks. This could still result as a benefit to the United States, as future projects will enjoy the well developed technology and expansive research that others have put into their own high speed systems. Currently, many countries have seen expansive growth around their larg- est cities, but have not seen as large of growth in others of smaller size as originally hoped. Table 1 shows comparisons of strengths and weaknesses of HSR in various countries.

\section{Conclusion}

The construction of an impressive high speed rail network can be a great asset to countries and travelers alike. HSR continues to eat away at the air travel network between cities within countries, saving travelers time and reducing emissions, though thresholds exist for the likelihood of attracting passengers. In an age of increasing fuel costs, high speed rail is offering an alternative way to move for many. As rail systems become more sophisticated and continue to increase in size in Europe and Asia, other countries are set to benefit from the technological improvements and research investments that countries are pouring in to this technology. Though the United States has not poured substantial resources into creating an HSR system, the country does stand to benefit from technology and successes of other countries. However, travelers and commuters have the most to gain in an era of improved transportation technology with faster travel times, easier mobility, less road congestion, and thriving livable communities surrounding the transportation nodes.

\section{Acknowledgements}

This work was financially supported by the Natural Science Foundation (No. 41071101), Fujian Natural Science Foundation (No. 2010J05099) and Special Fund for Scientific Research in Colleges and Universities (No. 2012121033).

\section{REFERENCES}

[1] K. Fender, “High Speed Rail Revolution,” Trains, Vol. 71, 
2011, pp. 24-31.

[2] D. Carol, M. Leger, W. Zuber and M, Downey, “An Introduction to High Speed Rail-A Multidisciplinary Challenge,” Velocity Network, No. 73, 2011, pp. 1-3.

[3] R. Tagaki, "High-Speed Railways: The Last 10 Years," Japan Railway \& Transport Review, Vol. 40, 2005, pp. 4-7.

[4] D. E. Andersson, O. Shyr and A. Lee, “The Successes and Failures of a Key Transportation Link: Accessibility Effects of Taiwan's High-Speed Rail," Annals Regional Science, Vol. 48, No. 1, 2012, pp. 203-223. doi:10.1007/s00168-010-0405-5

[5] M. Empelmann, D. Whittaker, E. Los and H. W. Dorgarten, "Taiwan High Speed Rail Project-Seismic Design of Bridges Across the Tuntzuchiao Active Fault," 13th World Conference on Earthquake Engineering, Vancouver, 1-6 August 2004, Paper No. 140.

[6] N. Tickner, “Taiwan High Speed Rail Project-Maintenance Facilities,” Velocity Network, No. 73, 2011, pp. 7376.

[7] L. Xinzhen, “Global Rail Tech Conductor,” 2010. http://www.bjreview.com/quotes/txt/2010-05/24/content_ 280720_2.htm

[8] I. Hobbs, "High Speed Power (Rail Electrification)," Power Engineer, Vol. 21, No. 2, 2007, pp. 32-35. doi:10.1049/pe:20070204

[9] P. Fairley, “China’s High-Speed Rail Revolution” 2010. http://www.technologyreview.com/news/417056/chinas-h igh-speed-rail-revolution/page/2/

[10] K. Fender, “TGV High Speed Hero,” Trains, Vol. 70, 2010, pp. 28-37.

[11] Cambridge Systematics, Inc., "High-Speed Rail: A Na- tional Perspective,” Amtrak Final Report, 2008. http://www.amtrak.com/ccurl/16/785/Amtrak-High_Spee d_Rail-A_National_Perspective.pdf

[12] Y. Hagler, “Terminal Capacity and High Speed Rail on the Northeast Corridor,” Velocity Network, No. 73, 2011, pp. 68-70.

[13] K. Hamlin, “China Bullet Trains Double Rail Stocks as Boom Brings Most Tracks in World,” 2010. http://www.bloomberg.com/news/2010-12-02/china-bulle t-trains-double-rail-stocks-as-boom-brings-most-tracks-in -world.html

[14] R. Vickerman, "High-Speed Rail in Europe: Experience and Issues for Future Development,” Vol. 31, No. 1, 1997, pp. 21-38.

[15] J. Murakami and R. Cervero, "High-Speed Rail and Economic Development: Business Agglomerations and Polic Implications,” University of California Transportation Center, Berkeley, 2010.

[16] H. Wouter, "High Speed Rail in Eastern Asia, 2011," Image 2011, 2013.

http://en.wikipedia.org/wiki/File:Eastern_Asia_HSR2011. svg

[17] Akwa, "High Speed Railway Network in Europe in 2012," Image 2010, 2013. http://en.wikipedia.org/wiki/File:High_Speed_Railroad_ Map_Europe_2011.svg

[18] Federal Railroad Association, "Map Showing US High Speed Rail Corridors as of July 9th, 2009,” Image 2009, 2013.

http://en.wikipedia.org/wiki/File:High_Speed_Rail_07-09 -2009.JPG 